\title{
A Qualitative Study of Influences Affecting EFL Learners' Self-Efficacy Beliefs In Preparatory Year
}

\author{
Malak Almohammadi \\ University of Exeter, UK
}

\begin{abstract}
With the growing importance of English proficiency in educational settings in non-English speaking countries, a great deal of research emphasizes the need to consider learners' beliefs as a crucial element to further understand learners' language proficiency. At the heart of these beliefs come learners' self-efficacy beliefs, as previous research has denoted a strong relationship between these beliefs and learners' performance. This study adopts a qualitative mode of inquiry and was designed to further understand EFL learners' self-efficacy beliefs and performance by looking at influences affecting these beliefs in an EFL context i.e., Saudi Arabia. This study comprises an in-depth analysis of interviews with 16 participants studying English as a foreign language in preparatory year in a Saudi university. The participants were selected deploying maximum variation and included both successful and less successful learners belonging to different performance levels. Data analysis revealed that besides the sources of self-efficacy, students' interpretations of their English attainments, others' expectations, academic and emotional support available to students were found to be related to their EFL self-efficacy beliefs. This study and its utilization of qualitative methods illuminate our understanding of EFL learners' self-efficacy beliefs as it sheds light on contextual and cultural influences on learners' self-efficacy beliefs.
\end{abstract}

Keywords: English as a foreign language; foundation year; maximum variation; sources of self-efficacy; support. 